\title{
Ação do acido pteroílglutâmico sobre o peso e a fosfatase alcalina do rim
}

\author{
Gilberto G. Villela \& Maria Isabel Mello \\ Laboratorio de Bioquimica da Divisão de Quimica e Farmacologia \\ do Instituto Oswaldo Cruz.
}

Os fatores necessarios ao crescimento do "Lactobacillus casei" (fator L. casei), tambem denominados genericamente de acido folico, foram em parte isolados quimicamente e sintetizados. O fator L. casei sintetico corresponde quimicamente ao acido pteroilglutâmico. ( $A P G$ ), sendo que os demais fatores como o de fermentação e o conjugado contém 2 e 6 moleculas de acido glutâmico (acido pteroíl-diglutamilglutamico e pteroíl-hexaglutamilglutâmico. O acido pteroilglutâmico foi obtido sinteticamente por Angier E colaboradores e mostrou-se dotado de propriedades identicas ao produto natural isolado anteriormente do fígado. $\mathrm{O}$ acido folico e os fatores a ele relacionados funcionam como vitaminas indispensaveis para a hematopoiese. Sómente doses muito elevadas são toxicas, bem que se tenham observado modificações histologicas dos rins de cobaios e coelhos tratados com doses acima de $5 \mathrm{mg} / \mathrm{Kg}$ de peso (Harned \& colaboradores) (1). Nenhuma outra referencia relativa á ação do APG sobre os rins foi publicada até a presente data (2). No decorrer de estudos sobre a toxicidade do APG um de nós verificou o aumento dos rins nos camondongos injetados com o APG mesmo em doses subtoxicas (3). Foi observado que o peso dos rins aumentam sensivelmente e que este aumento talvez fosse devido á precipitação do APG nos tubulos renais dada a sua pouca solubilidade. No presente trabalho procuramos estudar o peso e o teor em fosfatase alcalina dos rins de camondongos injetados com doses variaveis do APG. Nossos resultados mostraram que a fosfatase alcalina baixa mesmo quando se ministram doses pequenas do APG $(0,5 \mathrm{mg} / \mathrm{Kg})$. O aumento do peso dos rins não é devido á retenção de agua, mas á diminuição dos solidos excretados pelo rim $(\tau)$.

Foram empregados camondongos brancos de $20-23 \mathrm{gm}$ pertencentes todos á uma mesma linhagem e stock. Os animais foram submetidos a jejum de

Trabalho apresentado ao V Congresso Nacional de Quimica realizado em Janeiro de 1949 em Recife. 
16-20 hs. e sacrificados por exsanguinação. Os rins foram imediatamente removidos, pesados em balança de torsão e homogeinizados num gral de QUADRO I

Peso e fosfatase "alcalina" dos rins de camondongos adultos e normais.

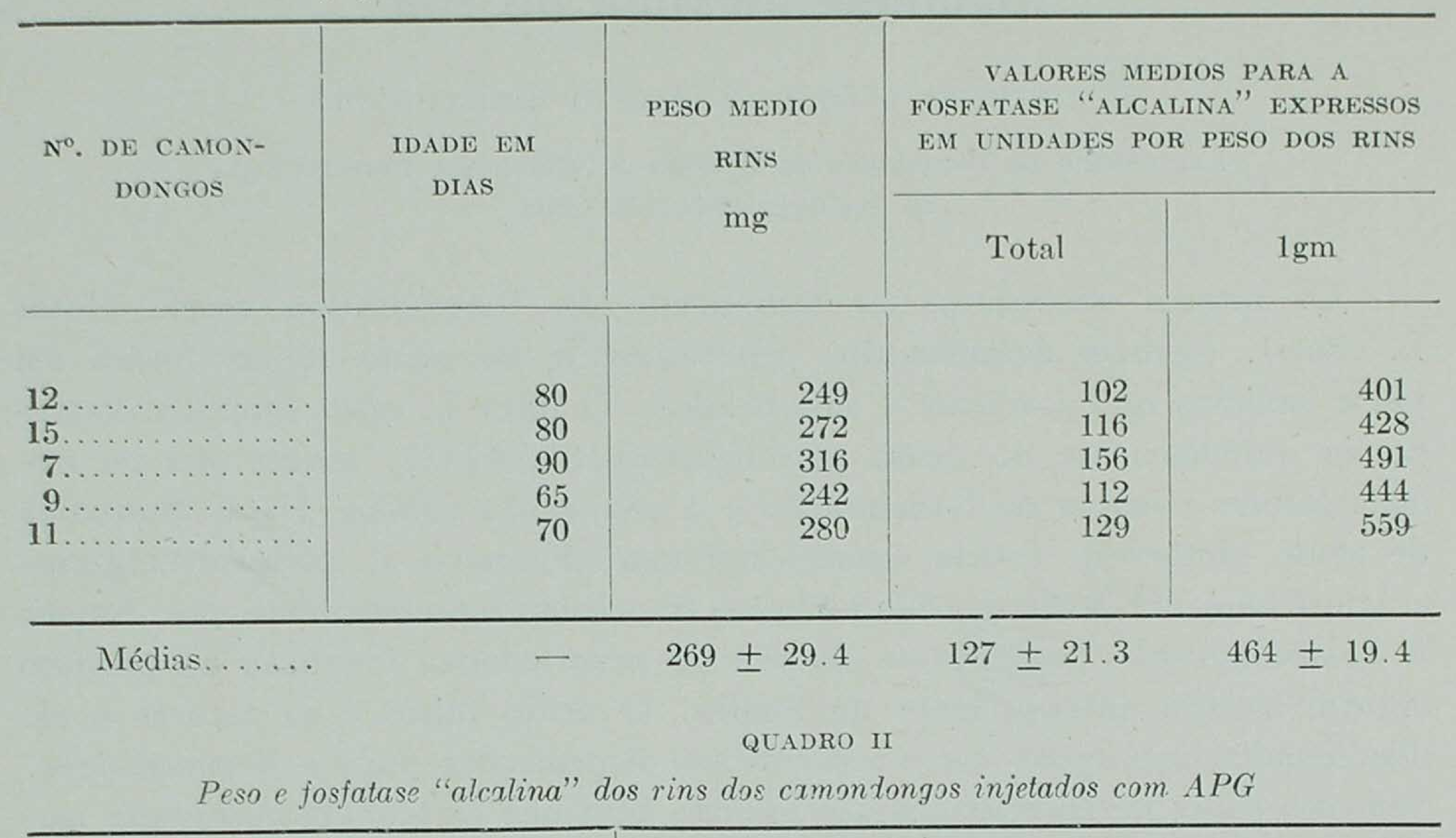

\begin{tabular}{|c|c|c|c|c|}
\hline \multirow{2}{*}{$\begin{array}{l}N^{\circ} \text {. DE CAMON- } \\
\text { DONGOS }\end{array}$} & \multirow{2}{*}{$\begin{array}{c}\text { DOSE } \\
\text { APG } \\
\mathrm{mg} / \mathrm{Kg}\end{array}$} & \multirow{2}{*}{$\begin{array}{c}\text { PESO } \\
\text { MÉDIO } \\
\text { rins }\end{array}$} & \multicolumn{2}{|c|}{$\begin{array}{l}\text { VALORES MÉDIOS PARA A } \\
\text { FOSFATASE "ALCALINA" EXPRESSOS } \\
\text { EM UNIDADES PARA O PESO DOS RINS }\end{array}$} \\
\hline & & & Total & $1 \mathrm{gm}$ de tecido \\
\hline $\begin{array}{c}10 \ldots \ldots \\
9 \ldots \ldots \\
8 \ldots \\
4 \ldots \ldots \\
13 \ldots \ldots \\
10 \ldots \\
6 \ldots \\
16 \ldots \\
13 \\
6 \\
3 \\
54 \ldots\end{array}$ & $\begin{array}{c}0,5 \\
0,75 \\
1,00 \\
5,00 \\
9500 \\
50,00 \\
75,00 \\
125,00 \\
250,00 \\
375,00 \\
500,00 \\
\text { controles }\end{array}$ & $\begin{array}{l}279 \\
295 \\
265 \\
272 \\
356 \\
370 \\
417 \\
457 \\
442 \\
409 \\
419 \\
269\end{array}$ & $\begin{array}{r}81 \\
133 \\
101 \\
100 \\
62 \\
58 \\
37 \\
50 \\
58 \\
82 \\
80 \\
111\end{array}$ & $\begin{array}{r}295 \\
454 \\
407 \\
313 \\
188 \\
168 \\
89 \\
112 \\
135 \\
162 \\
193 \\
450\end{array}$ \\
\hline
\end{tabular}

porcelana com agua distilada. O homogeinizado do rim diluido com $40 \mathrm{ml}$ de agua distilada por $\mathrm{gm}$ de tecido conforme recomendam Kochakian \& 
Fox (4). Os extratos foram filtrados a fim de retirar o tecido conjuntivo e diluidos 10 vezes. A determinação da fosfatase foi feita pelo metodo de King \& Armstrong ligeiramente modificado usando o fenilfosfato de sodio como substrato (5). A atividade fosfatásica foi determinada em $0.25 \mathrm{ml}$ do filtrado limpido tamponado para o $\mathrm{pH}$ de 9.8 e incubado com o substrato 15 minutos a $37^{\circ}$. O desenvolvimento da côr foi obtido com o reativo de Folin \& Ciocalteu; completou-se o volume para $10 \mathrm{ml}$ e a côr medida no fotocolorimento Lumetron com o filtro vermelho 650. As provas em branco foram feitas simultaneamente sendo omitido o periodo de incubação. Os resultados estão expressos em atividade de fosfatase alcalina, uma unidade

QUADRO III

Valores medios para o peso e a fosfatase "alcalina" dos rins dos camondongos normais e injetados com $A P G$.

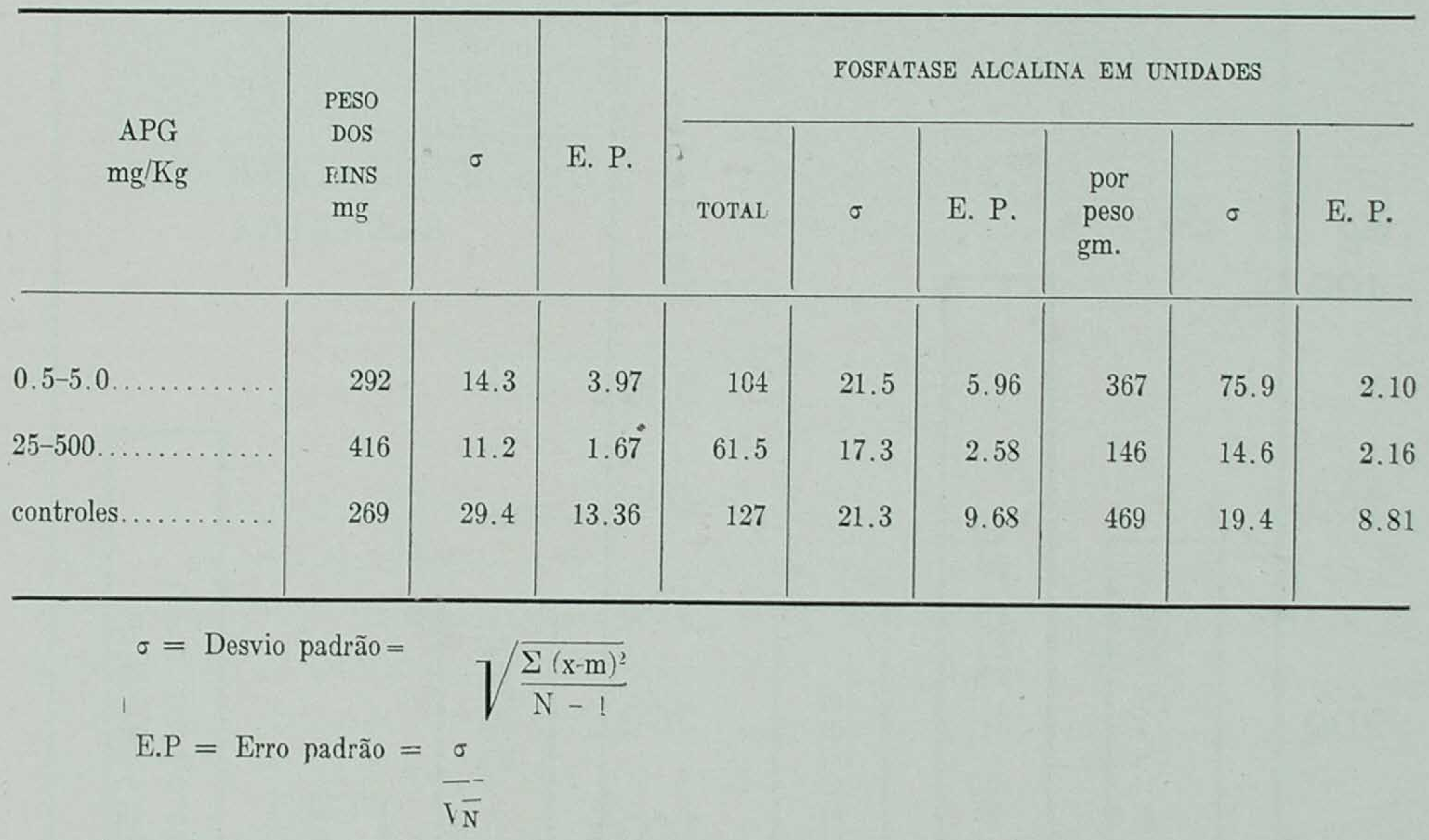

sendo equivalente a $1 \mathrm{mg}$ de fenol libertado pela hidrolise. Os valores obtidos são lidos numa curva padrão, previamente calibrada com quantidades conhecidas de fenol e tratadas pelo mesmo reagente e diluida para o volume de $10 \mathrm{ml}$. A solução do substrato de fenilfosfato de sodio foi preparada cada dois dias e guardada na geladeira. Em nossas experiencias as soluções mais velhas deram valores elevados.

Nestas experiencias empregamos sempre animais selecionados tendo o mesmo limite de idade e peso e submetidos a uma dieta padrão porque a idade 
influe no teor de fosfatase do rim conforme demonstaram Kochakian \& Fox (4). Os camondongos usados foram de preferencia os de 65-80 dias de idade $e$ pesando de $20-22 \mathrm{gm}$. No quadro I acham-se sumariados os valores para o peso e o teor em fosfatase alcalina dos rins de 54 camondongos normais em bom estado de nutrição. Os valores da ultima linha do quadro I referemse a animais em jejum de 24 hs. que mostraram um ligeiro aumento da enzima calculada por gm de tecido.

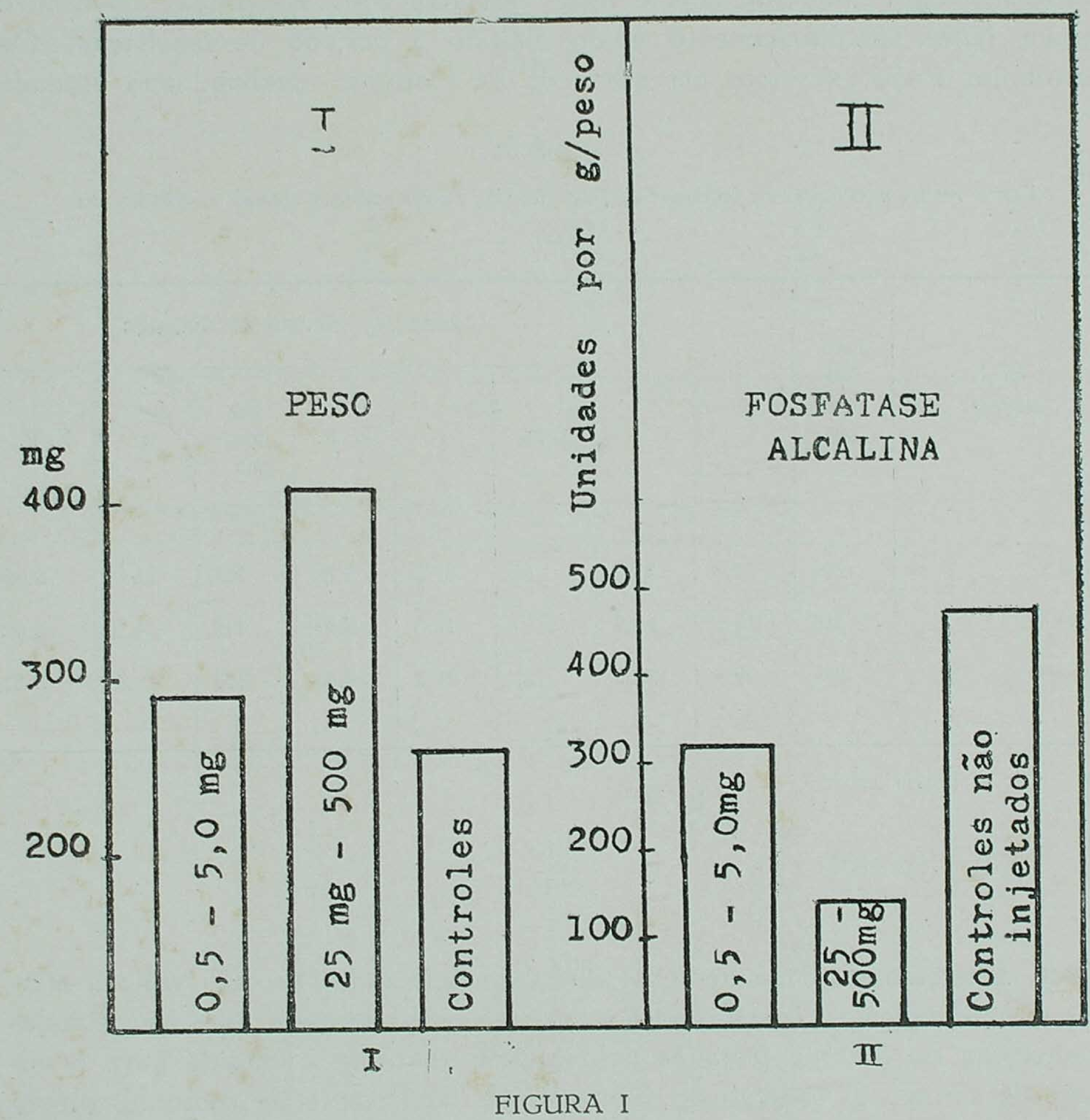

I Peso dos rins dos camondongos injetados com APG e dos animais controles não injetados.

II Fosfatase "alcalina" dos rins dos animais injetados com APG e dos controles não injetados. 
Os camondongos grupados e injetados subcutaneamente com doses crescentes de APG foram sacrificados 24 hs após a injeção. O LD50 (dose mortal $50 \%$ ) obtido para o APG por Harned \& colaboradores por via intraperitoneal foi de $600 \mathrm{mg} / \mathrm{Kg}$ (1). Para as doses injetadas subcutaneamente ribtivemos o LD50 de $375 \mathrm{mg} / \mathrm{Kg}$ de peso. Por conseguinte usámos neste trabalho doses menores para evitar a intoxicação aguda. Só verificamos a
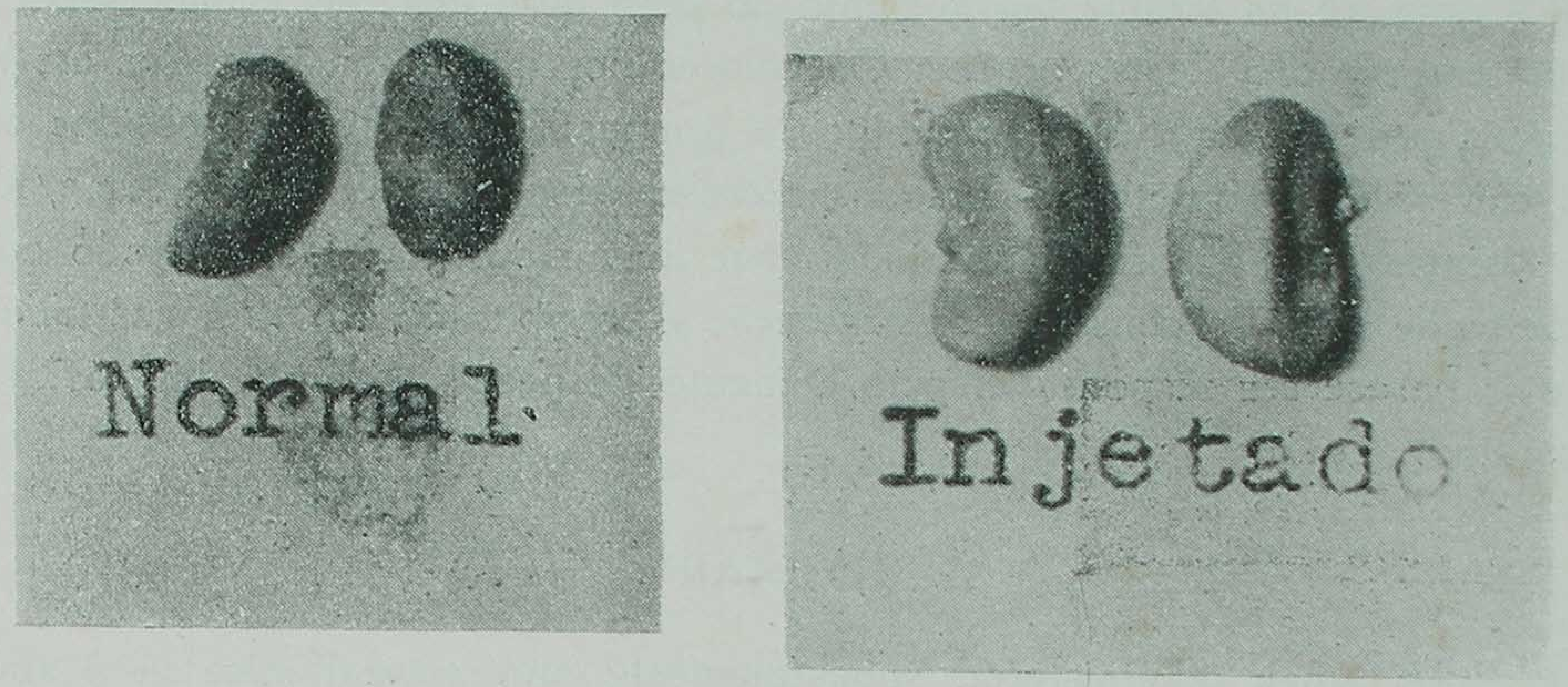

\section{FIGURA II}

Fotografias dos rins dos camondongos

I rins normais - II injetados

morte de animais com dose acima de $375 \mathrm{mg} / \mathrm{Kg}$. Como a dose de $0,5 \mathrm{mg} / \mathrm{Kg}$ tem um efeito pouco acentuado procurámos verificar si doses repetidas teriam ação cumulativa. Animais pesando $20-21 \mathrm{gm}$ foram injetados diariamente com $0,5 \mathrm{mg} / \mathrm{Kg}$ até completar a quantidade total de $5 \mathrm{mg} / \mathrm{Kg}$. O peso medio dos rins destes animais foi de $331 \mathrm{mg}$. e os valores da fosfatase alcalina de 100-312 U. para o rim total e gm de tecido.

A inspeção dos quadros II e III e das Figs. 1 e 2 mostra o efeito do APG sobre o peso e a fosfatase alcalina dos rins. A diferença entre as medias dos animais injetados e não injetados é duas vezes maior que o erro padrão da media para todos os grupos analizados (Quadro III). Estes resultados são portanto estatisticamente significantes (6). Mesmo que seja incluído o grupo de animais injetados com pequenas doses obtem-se um valor significante. $\mathrm{O}$ aumento do peso dos rins não se relaciona com o teor em agua dos mesmos desde que os valores médios para os animais normais e injetados não foi significante. 
Em uma experiencia foram usados 20 camondongos normais e 20 outros injetados com $0.5-25 \mathrm{mg} / \mathrm{Kg}$ sendo que os resultados para o $1 .^{\circ}$ grupo mostraram $76,3 \pm 0,3 \%$ de agua e para o $2 .^{\circ}$ grupo $75,4 \pm 0,8 \%$.

\section{SUMARIO}

O APG ministrado subcutaneamente a camondongos normais em injeção unica após 24 hs produz um aumento do peso total dos rins e uma baixa da fosfatase alcalina destes orgãos. Os valores normais foram baseados em ex. periencias feitas em 54 camondongos e comparados com outros obtidos com 88 camondongos injetados com doses crescentes de APG $(0,5-500 \mathrm{mg} / \mathrm{K})$. A fosfatase alcalina foi determinada por uma modificação do metodo colorimetro de King \& Armstrong. A retenção e precipitação do APG nos tubulos renais parece ser responsavel pelo aumento de peso e a baixa das fosfatase dos rins.

\section{SUMMARY}

PGA when administered subcutaneously into normal mice in a single injection produces after 24 hours an effective increase of the total weight and a decrease of the "alkaline" phosphatase of the Kidneys. Normal values based on 54 mice are reported and compared with those obtained from 88 mice injected with graded doses of PGA $(0.5 \mathrm{mg} / \mathrm{Kg}$ to $500 \mathrm{mg} / \mathrm{Kg}$ body weight). The "alkaline" phosphatase was determined by a slight modification of the colorimetric method of King \& Armstrong using disodium phenylphosphate as a substrate. It is suggested that the retention and precipitation of PGA in the renal tubuli could be responsible for the increased weight and decreased phosphatase activity of the kidneys.

\section{BIBLIOGRAFIA.}

1. Harned, B. K., Cunningham, R. W. Smith, H. D., E Clark, M. C.

1946. Pharmacological studies of Pteroylglutamic Acid, Ann. New York Acad. Sc. 48.289 .

2. Jukes, T. H. E Stokstad, E, L. R.

1948. Pteroylglutamic acid and related compounds, Physiol. Rev. 28,51.

3. Villela, G. G.

1947. Pteroylglutamic Acid (Folic acid) and Neoarsphenamine Toxicity, Arch. Bioch. 15.157. 
4. Kochakian, C. D., E Fox, P.

1944. The effect of castration and testosterone propionate on the "Alkaline" and "acid" phosphatase of the kidney, liver and intestine of the mouse, J. Biol. Chem. 153.669.

5. KING, E. J.

1948. Micro-Analysis in Medical Biochemistry, London, 1946, J. \& A, Churchil Ltd. pag. 57. e Villela, G. G., \& Mello M.I. : Determinação das fosfatases "Acida" e "Alcalina" do sôro, O Hospital 34,3,433.

6. Fisher, R. A.

1934. Statistical Methods for Research Workers, London, Oliver E Boyd, pag. 112.

7. Villela, G. G., e Mello, M. I.

1949. Effect of pteroylglutamic acid on weight and "alkaline" phosphatase of kidneys of the mouse. Proc. Soc. Exp. Biol. Med. 70, 453-454. 